\title{
PENGARUH SUPERVISI AKADEMIK DAN PELATIHAN PENELITIAN TINDAKAN KELAS TERHADAP KOMPETENSI PROFESIONAL GURU SEKOLAH DASAR SE-KECAMATAN UNDAAN KABUPATEN KUDUS
}

\author{
Aribowo, Su'ad, dan Achmad Hilal Madjdi \\ Magister Pendidikan Dasar Universitas Muria Kudus \\ Email: bowo.sundoro13@gmail.com, suadfadlan@gmail.com, achmad.hilal@umk.ac.id
}

\begin{tabular}{l} 
Info Artikel \\
\hline Sejarah Artikel \\
Diserahkan 20 Februari 2020 \\
Direvisi 18 April 2020 \\
Direvisi 30 April 2020 \\
Disetujui 15 Mei 2020 \\
\hline
\end{tabular}

Keywords:

academic supervision, classroom action reseach training, teacher profesional competence.

\begin{abstract}
The purpose of this study is 1) to know effect of academic supervision on the professional competencies of elementary school teacher, 2) to know the effect of classroom action research training on the professional competencies of elementary school teachers, 3) to know effect of academic supervision and classrooom action research training on the professional competencies of elementary school teacher.

The subject of this study werw all elementary school teachers in all subdistrict of Undaan Kudus regency. This study uses a quantitative contribution method with regression analysis techniques. Respondents were selected using a purposive sampling technique. Data collection research using questionaire. The validity of data uses construct validity bay way of experiential juggment. Data analysis was perfomed using regression analysis techniques in the form of simple and multiple regression.

The results of study showed that academic supervision had an effect on techer professional competence of 32,0 \%. Whereas classroom action research training has an effect on teacher professional competence of $39,1 \%$. Academic supervision and classroom action research training together have an effect on teacher professional competence of 46,6\%.
\end{abstract}

\begin{abstract}
Abstrak
Tujuan penelitian ini yaitu : 1) mengetahui pengaruh supervisi akademik terhadap kompetensi profesional guru SD Se-kecamatan Undaan Kabupaten Kudus , 2) mengetahui pengaruh pelatihan penelitian tindakan kelas terhadap kompetensi profesional guru SD SeKecamatan Undaan Kabupaten Kudus, 3) mengetahui pengaruh supervisi akademik dan pelatihan penelitian tindakan kelas terhadap kompetensi profesional guru SD SeKecamatan Undaan Kabupaten Kudus.

Subyek penelitian ini yaitu seluruh guru pegawai negeri sipil sekolah dasar Se-Kecamatan Undaan Kapbupaten Kudus. Penelitian ini menggunakan metode kuantitatif kontribusional dengan teknik analis regresi. Responden sebanyak 111 orang yang dipilih menggunakan teknik purposif sampling. Pengumpulan data penelitian menggunakan kuesioner. Validitas data menggunakan validitas kontruk dengan cara expert jugement. Analisis data menggunakan teknik analisis regresi berupa regresi sederhana dan ganda.

Hasil penelitian terlihat bahwa supervisi akademik berpengaruh terhadap kompetensi profesional guru sebesar 32,0\%. Sedangkan pelatihan PTK berpengaruh terhadap kompetensi profesional guru sebesar $39,1 \%$. Supervisi akademik dan pelatihan PTK bersama-sama berpengaruh terhadap kompetensi profesional guru sebesar $46.6 \%$.
\end{abstract}




\section{PENDAHULUAN}

Di era revolusi industri 4.0 sekarang ini semua dikerjakan dengan teknologi modern dan tenaga yang profesional. Perubahan itu juga terjadi dibidang pendidikan. Guru di era revolusi industri 4.0 dituntut bekerja dengan profesional. Apalagi dengan adanya tunjangan profesi guru harus lebih profesional dalam bekerja.

Guru dituntut bisa mengajar sesuai kompetensinya hal ini tersirat dalam Peraturan Pemerintah Nomor 19 Tahun 2005 tentang Standar Nasional Pendidikan (SNP) pada pasal 28 ayat 3 butir $\mathrm{c}$ disebutkan bahwa kompetensi profesional adalah kemampuan menguasai materi pembelajaran secara mendalam untuk membimbing siswa memenuhi standar kompetensi yang ditetapkan dalam Standar Nasional Pendidikan. Kompetensi Profesional Guru juga dapat dilihat dari Uji Kompetensi Guru (UKG), karena guru akan diberikan tes pada kemampuan pedagogik dan profesional.

Dari hasil Uji Kompetensi Guru (UKG) tahun 2015 di Kecamatan Undaan mendapatkan nilai rata-rata 62,47 dengan persentase guru yang tidak lulus KKM 28,10\%. Dari data diatas permasalahan yang mendesak dicarikan solusi yaitu kompetensi profesional guru. Diharapkan solusinya dapat meningkatkan kompetensi profesional guru.

Bafadal (2009) menyatakan bahwa kegiatan supervisi dilaksanakan continue dapat meningkatkan kompetensi profesional guru. Guru perlu mendapat bantuan dari pembimbing supaya dapat memaksimalkan fungsinya secara profesional. Kegiatan supervisi salah satunya yaitu supervisi akademik. Pratiwi (2013) menyatakan supervisi akademik memiliki pengaruh positif dan signifikan terhadap kompetensi profesional guru. Supervisi akademik memberikan kontribusi terhadap peningkatan kompetensi profesional guru.

Workneh and Tassew (2013) menyatakan bahwa teacher training, capacity building and work experience have positive impact on education quality. Yang artinya pelatihan guru, peningkatan kapasitas, dan pengalaman kerja memiliki dampak positif terhadap kualitas pendidikan. Dengan adanya pelatihan guru dapat meningkatkan kualitas pendidikan salah satu contoh yaitu pada kompetensi profesional guru.

Hardoko, Haryono, dan Yusuf (2017) menyebutkan supervisi akademik yaitu kegiatan bantuan kepada guru untuk membantu guru dalam proses Kegiatan Belajar Mengajar $(\mathrm{KBM})$ terdiri dari kegiatan perencanaan, pelaksanaan, dan penilaian. Supaya tercapai tujuan pembelajaran. Sehingga supervisi akademik dapat meningkatkan kualitas pembelajaran.

Arikunto dan Yuliana (2013) menyebut bahwa inti dari supervisi akademik terletak pada kegiatan akademik langsung berkaitan dengan proses KBM. Disebutkan Mulyasa (2015) bahwa tujuan supervisi akademik yaitu meningkatkan kemampuan profesional guru dan peningkatan kualitas pembelajaran.

Sagala (2010) membagi teknik supervisi akademik menjadi dua yaitu teknik supervisi akademik individual dan teknik supervisi akademik kelompok. Pelaksanaan supervisi profesionalitas dan kompetensi keguruan yang baik menurut Kompri (2015) dapat dilakukan dengan cara : 1) memotivasi guru bekerja dengan baik, 2) mendorong guru tidak bekerja monoton, 3) kepala sekolah memberi contoh dan guru juga disiplin serta memberi sanksi bagi yang melanggar, 4) menghimbau guru meningkatkan profesinya.

Azhar dalam Kompri (2015) menyebutkan bahwa cara untuk memanfaatkan hasil supervisi akademik yaitu: 1) memberikan saran-saran perbaikan dari masalah yang ditemukan, 2) melaporkan penyimpangan agar dilaksanakan sebagai mana mestinya, 3) melaksanakan konferensi kasus, 4) melaporkan hasil supervisi kepada pengawas atau pejabat pendidikan yang berwenang.

Dari uraian diatas dapat disimpulkan supervisi akademik yaitu bantuan profesional kepada guru yang sistematis, pengamatan cermat, dan umpan balik yang obyektif. Supervisi akademik merupakan bantuan kepada guru dalam hal akademik pada proses perencanaan, pelaksanaan dan penilaian supaya tujuan pembelajaran dapat tercapai. Pada penelitian ini hanya menitik beratkan pada proses pelaksanaan dan tindak lanjut supervisi akademik saja. Dengan adanya supervisi akademik akan meningkatkan kompetensi profesional guru.

Dessler (Mulyanti 2018) menyebut pelatihan merupakan suatu proses mengajarkan ketrampilan yang diperlukan karyawan baru dalam melaksanakan pekerjaannya. Menurut 
Mangkunegara (Mulyanti 2018) tujuan pelatihan adalah peningkatan penghayatan jiwa ideologi, peningkatan produktivitas kerja, peningkatan kualitas kerja, peningkatan sikap moral dan semangat kerja.

Menurut Bangun (2012) tingkatan penilaian pelatihan dibagi menjadi empat yaitu: 1) Reaksi, 2) Pembelajaran, 3) Perilaku, 4) Hasil Pelatihan. Menurut Wardhani (2014) menyatakan bahwa penelitian tindakan kelas (PTK) merupakan penelitian yang dilaksanakan guru saat dikelas melalui refleksi diri bertujuan memperbaiki kinerjanya dan meningkatkan hasil belajar siswa. Menurut Tampubolon (2014) tujuan khusus PTK yaitu memperbaiki kualitas proses KBM dikelas secara berkelanjutan agar hasil belajar siswa meningkat.

Dari pendapat ahli diatas dapat disimpulkan bahwa pelatihan merupakan pengalaman belajar melakukan perubahan agar dapat terjadi peningkatan baik pengetahuan maupun ketrampilan dalam melakukan pekerjaan. Penilaian pelatihan ada empat yaitu: Reaksi, Pembelajaran, Perilaku, dan Hasil Pelatihan. PTK yaitu tindakan yang dilakukan guru yang bersifat refleksi untuk memperbaiki pembelajaran guru didalam kelas dalam upaya meningkatkan hasil belajar siswa. Manfaat Penelitian Tindakan Kelas yaitu menghasilkan PTK untuk meningkatkan mutu pembelajaran, menumbuhkan kebiasaan-kebiasaan menulis penelitian bagi guru, adanya kerjasama antar guru dalam memecahkan masalah pembelajaran, peningkatan hasil belajar siswa, dan terwujud pembelajaran yang menyenangkan.

Menurut Mulyasa (2013) kompetensi profesional merupakan kemampuan guru dalam menguasai materi pembelajaran dalam rangka membimbing siswa mendapatkan kompetensi yang ditetapkan. Pengetahuan profesional mempunyai landasan yang dijadikan petunjuk guru dalam mengembangkan kompetensi profesionalnya. Dalam permendiknas No.16 Tahun 2007 dijelaskan bahwa ada lima aspek kompetensi profesional guru yaitu: 1) menguasai materi yang membantu dalam mengajar, 2) Menguasai Standar Kompetensi dan Kompetensi dasar saat mengajar, 3) mengembangkan materi pembelajaran yang kreatif, 4) mengembangkan sikap profesional yang berkesinambungan, 5) Mampu menggunakan perkembangan teknologi dan komunikasi dalam mendukung pembelajaran. Menurut Mulyasa (2007) Kompetensi profesional guru dapat dijelaskan sebagai berikut: Pemahaman tentang SNP dalam mengembangkan KTSP, Mampu menguasai materi maupun menguasai kelas, Menggunakan media dan sumber belajar yang relevan.

Berdasarkan uraian diatas dapat disimpulkan bahwa kompetensi profesional adalah kemampuan guru menguasai materi pembelajaran dalam membimbing peserta didik mendapatkan hasil belajar yang maksimal. Dalam penelitian ini kompetensi profesional yang dibahas yaitu: penguasaan materi oleh guru, penguasaan SK dan KD dalam pembelajaran, pengembangan materi pembelajaran secara kreatif, mengembangkan sikap profesional yang berkelanjutan, dan mampu memanfaatkan teknologi dan komunikasi. Strategi mengembangkan kompetensi profesional guru yaitu: meningkatkan profesionalisme guru melalui supervisi akademik dan meningkatkan kompetensi profesional guru melalui pelatihanpelatihan guru.

Berdasarkan uraian diatas maka tujuan penelitian ini yaitu untuk mengetahui pengaruh supervisi akademik terhadap kompetensi profesional guru, mengetahui pengaruh pelatihan PTK terhadap kompetensi profesional guru, mengetahui pengaruh supervisi akademik dan pelatihan PTK terhadap kompetensi profesional guru.

\section{METODE PENELITIAN}

Rancangan dalam penelitian ini menggunakan penelitian survey dengan menggunakan pendekatan kuantitatif kontribusional. Populasi penelitian ini merupakan seluruh guru PNS di UPT pendidikan Kecamatan Undaan Kabupaten Kudus. Data populasi sebanyak 191 orang.

Dalam penelitian ini metode pengambilan sampel yaitu secara purposif (sampling dengan kriteria tertentu) yaitu guru SD yang PNS, minimal berijazah S1 karena kualifikasi guru sekarang harus minimal S1 dan berusia antara 24 s.d 55 tahun dengan alasan guru yang memiliki kriteria tersebut pada umumnya lebih produktif. Selain itu kriteria lain yaitu guru yang mengikuti pelatihan PTK satu kali dan tempat pelatihan tidak menjadi 
faktor penentu sampel. Data sampel penelitian sebanyak 111 orang.

Instrumen penelitian ini yaitu menggunakan kuesioner. Instrumen disusun penulis berisi pernyataan tentang supervisi akademik, pelatihan PTK, dan kompetensi profesional guru. Instrumen dibuat indikator untuk membuat butir pertanyaan. Sebelum digunakan instrumen terlebih dahulu dilakukan uji validitas dengan cara expert jugement yaitu menguji instrumen yang telah dibuat oleh dosen ahli, kemudian instrumen diuji cobakan kepada responden sejumlah 30 orang guru PNS SD di Kabupaten Kudus sesuai kriteria sampel, yang merupakan responden try out yang tidak terlibat dalam pengambilan data.

Analisis data yang dipakai dalam penelitian ini yaitu menggunakan teknik statistika deskriptif dan analisis regresi. Langkah dalam menganalisis data dengan menyeleksi dan mengklasifikasikan data, kemudian melakukan analisis deskripsi karakteristik responden dan variabel dengan menggunakan SPSS. Melaksanakan uji pra syarat analisis, uji hipotesis, dan melakukan analisis data dalam menjawab rumusan masalah.

\section{HASIL DAN PEMBAHASAN}

Jumlah kuesioner yang telah disebar oleh peneliti adalah sejumlah 111 kuesioner. Kuesioner yang kembali pada peneliti sejumlah 111 kuesioner.

Pelaksanaan supervisi akademik pada guru SD se-Kecamatan Undaan Kabupaten Kudus dari data yang diperoleh peneliti berdasar 111 responden menunjukkan bahwa pelaksanaan supervisi akademik diperoleh perhitungan statistik deskriptif yaitu means 49,95; median 49,00; standart deviation 8,662; range 37; minimum 30; maximum 67. Pada pelatihan PTK diperoleh perhitungan statistik deskriptif yaitu mean 58,11; median 58,00; standart deviation 12,023; range 60; minimum 20; maximum 80. Pada kompetensi profesional guru diperoleh perhitungan statistik deskriptif yaitu mean 82,36; median 82,00; standart deviation 9,937; range 48; minimum 61; maximum 109.

Supervisi akademik yang berjalan cukup baik ternyata berpengaruh terhadap kompetensi profesional guru. Sesuai dengan analisis menggunakan regresi sederhana diketahui $\mathrm{t}$ hitung 7,156 dengan nilai signifikansi $0,00<$ 0,05, maka Ho ditolak dan $\mathrm{Ha}$ diterima. Artinya ada pengaruh supervisi akademik terhadap kompetensi profesional guru SD seKecamatan Undaan Kabupaten Kudus. Besar pengaruhnya sebesar $32,0 \%$.

Pengaruh supervisi akademik terhadap kompetensi profesional guru dapat dilihat pada tabel 1 dibawah ini.

Tabel 1. Pengaruh supervisi akademik terhadap kompetensi pofesional guru SD se-Kecamatan Undaan Kabupaten Kudus

\begin{tabular}{ccc}
\hline $\begin{array}{c}\mathrm{t} \\
\text { hitung }\end{array}$ & Nilai sig & $\begin{array}{c}\text { Besar } \\
\text { Kontribusi } \\
(\%)\end{array}$ \\
\hline 7,156 & 0,000 & 32,0 \\
\hline
\end{tabular}

Berdasarkan data diatas dapat disimpuklan bahwa supervisi akademik berpengaruh terhadap kompetensi profesional guru sebesar $32,0 \%$.

Hasil dilapangan dalam penelitian ini menunjukkan bahwa pelatihan PTK berpengaruh terhadap kompetensi profesional guru. Hal ini sesuai dengan hasil analisis data menggunakan analisis regresi sederhana diketahui $\mathrm{t}$ hitung 8,372 dengan nilai signifikansi $0,00<0,05$, maka Ho ditolak serta Ha diterima. Artinya bahwa terdapat pengaruh pelatihan PTK terhadap kompetensi profesional guru SD se-Kecamatan Undaan Kabupaten Kudus. Besar pengaruhnya yaitu 39,1\%.

Pengaruh pelatihan PTK terhadap kompetensi profesional guru dapat dilihat dalam tabel 2 dibawah ini.

Tabel 2. Pengaruh pelatihan PTK terhadap kompetensi profesional guru SD se-Kecamatan Undaan Kabupaten Kudus

\begin{tabular}{ccc}
\hline t hitung & $\begin{array}{c}\text { Nilai } \\
\text { sig }\end{array}$ & $\begin{array}{c}\text { Besar } \\
\text { Kontribusi } \\
(\%)\end{array}$ \\
\hline 8,372 & 0,000 & 39,1 \\
\hline
\end{tabular}

Dari data diatsa dapat disimpulkan bahwa pelatihan PTK berpengaruh terhadap kompetensi profesional guru sebesar 39,1\%.

Berdasarkan hasil SPSS nilai probabilitas signifikansinya sebesar $0,00=0 \%$ 
$<5 \%$, maka Ho ditolak serta Ha diterima. Hal ini menunjukkan bahwa ada pengaruh supervisi akademik dan pelatihan PTK terhadap kompetensi profesional guru SD se-Kecamatan Undaan Kabupaten kudus. Besar pengaruhnya sebesar $46,6 \%$.

\section{PEMBAHASAN}

Pada variabel supervisi akademik menurut data statistik deskriptif diperoleh nilai rata-rata sebesar 49,95 yang terletak pada interval 42-54 dengan kriteria cukup baik. Dapat dikatakan bahwa supervisi akademik Kepala Sekolah SD se-Kecamatan Undaan Kabupaten Kudus adalah cukup baik. Teknik supervisi yang digunakan oleh Kepala Sekolah meliputi teknik yang bersifat individual dan bersifat kelompok (Sagala, 2010).

Pelaksanaan supervisi akademik yang sudah cukup baik tersebut, agar hasilnya lebih baik lagi maka diperlukan adanya tindak lanjut supervisi akademik. Kemudian selain itu, bagaimana cara Kepala Sekolah melakukan supervisi akademik merupakan pemanfaatan hasil supervisi akademik. Artinya perlu adanya tindak lanjut terhadap hasil supervisi akademik, agar dapat memberikan dampak nyata peningkatan kompetensi profesional guru.

Data dilapangan menunjukkan supervisi akademik yang sudah berjalan cukup baik tersebut ternyata berpengaruh terhadap kompetensi profesional guru. Hal ini ditunjukkan dari hasil analisis data menggunakan regresi sederhana dimana diketahui nilai $\mathrm{t}$ hitung 7,156 dengan nilai signifikansi $0,00<0,05$, maka Ho ditolak dan $\mathrm{Ha}$ diterima, yang bearti ada pengaruh supervisi akademik terhadap kompetensi profesional guru SD se-Kecamatan Undaan Kabupaten Kudus. Besar kontribusinya adalah $32 \%$. Hasil penelitian yang dilakukan memiliki persamaan dengan penelitian Aswidirno (2015) dan penelitian Zulfikar (2017). Dari dua penelitian tersebut diperoleh informasi bahwa supervisi akademik mempunyai kontribusi yang sangat penting dalam meningkatkan kompetensi profesional guru dalam kualitas pengajaran yang dilakukan oleh guru di sekolah.

Pada variabel pelatihan PTK menurut hasil analisa statistik deskriptif diperoleh nilai rata-rata sebesar 58,11 yang terletak pada interval 40-60 dengan kriteria cukup baik.
Dapat dikatakan bahwa pelatihan PTK di Kecamatan Undaan Kabupaten Kudus adalah cukup baik. Ada empat tingkat penilaian atas pelatihan antara lain yaitu: Reaksi, Pembelajaran, Perilaku dan Hasil Pelatihan (Bangun, 2012:208-210). Demikian juga menurut Mangkunegara dalam Mulyanti (2018) membahas tujuan pelatihan dan pengembangannya. Setelah mengikuti pelatihan PTK para guru SD di Kecamatan Undaan Kabupaten Kudus merasa puas dengan materi pelatihan PTK yang diikuti.

Berdasarkan hasil penelitian, diketahui bahwa pelatihan PTK di Kecamatan Undaan sudah berjalan cukup baik. Hal tersebut ditunjukkan dengan hasil analisis data menggunakan regresi sederhana dimana diketahui nilai $\mathrm{t}$ hitung 8,372 dengan nilai signifikansi $0,00<0,05$, maka Ho ditolak dan Ha diterima, yang bearti ada pengaruh pelatihan PTK terhadap kompetensi profesional guru SD se-Kecamatan Undaan Kabupaten Kudus. Besar kontribusinya adalah 39,1\%. Hasil penelitian serupa yang dilakukan memiliki persamaan dengan riset Eliyanto (2013) yang menyebut bahwa pelatihan mempunyai kontribusi yang sangat penting dalam meningkatkan kompetensi profesional guru disekolah.

Berdasarkan hasil output SPSS diperoleh nilai probabilitas signifikansi $(\mathrm{sig})=$ $0,00=0 \%<5 \%$, ini bearti Ho ditolak dan $\mathrm{Ha}$ diterima. Hal ini bearti terdapat pengaruh variabel supervisi akademik dan pelatihan PTK secara bersama-sama terhadap variabel kompetensi profesional guru. Besar kontribusinya yaitu 46,4\%. Hasil tersebut menunjukkan bahwa supervisi akademik dan pelatihan PTK dapat meningkatkan kompetensi profesional guru SD. Dari hasil penelitian diatas bisa membuktikan hipotesa yang telah dibuat peneliti.

Hasil penelitian yang dilakukan memiliki persamaan dengan penelitian Ismaya (2013), riset Kadis (2015), penelitian Nurkhan (2016), riset Prihono dan Supahar (2018), serta penelitian Iswan dan Hadidah (2019). Adapun persamaan yang dimaksud yaitu menjadikan guru pada subyek penelitian. Sedangkan perbedaanya pada fokus riset yang dilakukan.

$$
\text { Penelitian Ismaya (2013) }
$$

mengemukakan bahwa seorang guru haruslah profesional serta berkarakter. Oleh karena itu 
Aribowo, Su'ad, dan Achmad Hilal Madjdi

PENGARUH SUPERVISI AKADEMIK DAN PELATIHAN PENELITIAN TINDAKAN KELAS ...

REFLEKSI EDUKATIKA : Jurnal Ilmiah Kependidikan, Volume 10, Nomor 2, Juni 2020, hlm. 216-222

lulusan FKIP UMK merupakan seorang calon guru yang profesional dan berkarakter Cerdas dan Santun. Sementara itu riset Kadis (2015) menemukan bahwa melalui penerapan supervisi klinis dengan menggunakan pendekatan Humanistik teknik Implant, kompetensi guru dalam penyususnan RPP tematik saintifik di Dabin I Gugus "SukarnoHatta" terjadi peningkatan yang signifikan yaitu dari pengamatan awal 53,13 \%, siklus I $74,09 \%$, siklus II $88,28 \%$.

Selanjutnya penelitian Nurkhan (2016) menemukan bahwa model pendampingan yang dilakukan terbukti berhasil dan effektif dalam meningkatkan kemampuan pengelolaan penilian bagi guru SD Sasaran Kurikulum 2013, hal ini bisa dibuktikan dengan analisis data yang menunjukkan ada peningkatkan, yaitu rata-rata naik 28,7 poin atau $23,9 \%$. riset Prihono dan Supahar (2018) menemukan bahwa (1) pencapaian rerata nilai prestasi kerja guru secara keseluruhan sebesar 71,00 dari rentang skor 0-100 dan (2) terdapat 4 kecamatan dan 18 Sekolah Dasar dengan kategori rendah dalam penilaian prestasi kerja guru sekolah laboratorium Universitas PGRI Yogyakarta.

\section{SIMPULAN}

Berdasarkan analisis data dan hasil penelitian saat dilapangan dapat disimpulkan bahwa terdapat pengaruh supervisi akademik terhadap kompetensi profesional guru SD seKecamatan Undaan Kabupaten Kudus sebesar $32.0 \%$. Ada pengaruh pelatihan PTK terhadap kompetensi profesional guru SD se-Kecamatan Undaan Kabupaten Kudus sebesar 39,1\%. Serta terdapat pengaruh supervisi akademik dan pelatihan PTK terhadap kompetensi profesional guru SD se-Kecamatan Undaan Kabupaten Kudus sebesar $46,6 \%$.

Jadi hasil temuan diatas sudah membuktikan hipotesa penelitian yaitu ada pengaruh supervisi akademik terhadap kompetensi profesional guru, terdapat pengaruh pelatihan PTK terhadap kompetensi profesional guru, serta terdapat pengaruh supervisi akademik dan pelatihan PTK terhadap kompetensi profesional guru.

\section{DAFTAR PUSTAKA}

Arikunto Suharsimi, dan Yuliana, Ani. 2013. Manajemen Pendidikan. Sleman: Graha Cendekia.

Aswindirno, Sukmawati, \& Masluyah Suib. 2015. Pengaruh Supervisi Akademik dan Partisipasi Guru dalam KKG Terhadap Kompetensi Profesional Guru SD Kecamatan Sajad. Jurnal Administrasi Pendidikan FKIP Untan

Bafadal, I.2009.Peningkatan Profesionalisme Guru Sekolah Dasar Dalam Kerangka Manajemen Peningkatan Mutu Berbasis Sekolah. Jakarta: Bumi Aksara.

Bangun, Wilson. 2012. Manajemen Sumber Daya Manusia. Jakarta: Erlangga

Eliyanto, Udik Budi Wibowo. 2013. Pengaruh Jenjang Pendidikan, Pelatihan, Dan Pengalaman Mengajar Terhadap Profesionalisme Guru Sma Muhammadiyah Di Kabupaten Kebumen. Jurnal Akuntabilitas Manajemen Pendidikan 1 (1).

Hardono, Haryono, \& Amin Yusuf. 2017. Kepemimpinan Kepala Sekolah, Supervisi Akademik, dan Motivasi Kerja dalam Meningkatkan Kinerja Guru. Educational Mangement, 6 (1) 26-33

Ismaya, Erik Aditia. 2013. Guru Yang Cerdas Dan Santun, Profil Guru Profesional Dan Berkarakter Lulusan Universitas Muria Kudus. Prosiding Seminar Nasional yang Peranan Guru Profesional dan Berkarakter dalam Pembangunan Sumber Daya Manusia di Era Global PGSD Universitas Muria Kudus 30 Maret 2013, 96-106.

Iswan, dan Hadidah, Indah. 2019. Pengaruh Disiplin Kerja Guru Terhadap Disiplin Belajar Siswa Sekolah Dasar. Refleksi Edukatika : Jurnal Ilmiah Kependidikan, 10 (1): 121-127.

Kadis. 2015. Peningkatan Kemampuan Guru Dalam Pengelolaan Pembelajaran 
Tematik Saintifik Melalui Supervisi Klinis Pendekatan Humanistik Teknik Implant Bagi Guru Kelas Iv Dabin I Gugus "Sukarno-Hatta" Dinas Pendidikan Kecamatan Gabus Kabupaten Pati Pada Semester I Tahun Pelajaran 2014/2015. Refleksi Edukatika : Jurnal Ilmiah Kependidikan, 5 (1).

Kompri. 2015. Manajemen Sekolah: Orientasi Kemandirian Kepala Sekolah. Yogyakarta: Pustaka Belajar.

Peraturan Pemerintah Republik Indonesia Nomor 19 Tahun 2005 tentang Standar Nasional Pendidikan.

Mulyanti, Anita Surya. 2018. Pengaruh Pelatihan dan Lingkungan Kerja terhadap Kinerja Guru dengan Kepuasan Kerja sebagai Variabel Intervening di SD Muhammadiyah Condong Catur. (Skripsi). Yogyakarta: Universitas Islam Indonesia

Mulyasa. 2007. Standar Kompetensi dan sertifikasi guru. Bandung: PT Remaja Rosdakarya.

Mulyasa, H. E. 2013. Uji Kompetensi dan Penilaian Kinerja Guru. Bandung: Rosda Karya.

Mulyasa. 2015. Manajemen dan Kepemimpinan Kepala Sekolah. Jakarta: Bumi Aksara.

Nurkhan. 2016. Peningkatan Kemampuan Pengelolaan Penilaian Kurikulum 2013 Melalui Pendampingan Bagi Guru Sekolah Dasar. Refleksi Edukatika : Jurnal Ilmiah Kependidikan, 7 (1): 4555.
Pratiwi, Asih. 2013. Pengaruh Pelaksanaan MGMP IPA Terpadu san Supervisi Akademik oleh Kepala Sekolah Terhadap Kompetensi Profesional Guru IPA SMP/MTS se-Kota Magelang. (Skripsi). Yogyakarta: Universitas Negeri Yogyakarta

Prihono, Eko Wahyunanto., dan Supahar. 2018. The Measurement Of Professional Competency To School Teacher's Achievement At PGRI University Yogyakarta Laboratory. Refleksi Edukatika : Jurnal Ilmiah Kependidikan, 8 (2): 114-123.

Sagala, Syaiful. 2010. Supervisi Pembelajaran dalam Profesi Pendidikan. Bandung: Alfabeta

Saifuddin, Azwar. 2013. Reliabilitas dan Validitas. Yogyakarta: Pustaka Belajar

Sugiyono. 2015. Metode Penelitian Pendidikan Pendekatan Kuantitatif, Kualitatif, $R \& D$. Bandung: Alfabeta.

Sugiyono. 2010. Statistika Untuk Penelitian. Bandung: Alfabeta.

Tampubolon, Saur. 2014. Penelitian Tindakan Kelas untuk Pengembangan Profesi Pendidik dan Keilmuan. Jakarta: Erlangga.

Wardhani, Kuswaya Wihardit. 2014. Penelitian Tindakan Kelas. Tangerang Selatan: Universitas Terbuka.

Workneh, A \& Tassew, W. 2013. Teacher Training and Development in Ethiopia. Young Lives Journal.

Zulfikar, Yusrikal, dan Sakdiah Ibrahim. 2017. Supervisi Akademik Oleh Kepala Sekolah Dalam Meningkatkan Kompetensi Profesional Guru. Jurnal Magister Pendidikan Pasca Sarjana Universitas Syiah Kuala, 5 (3). 